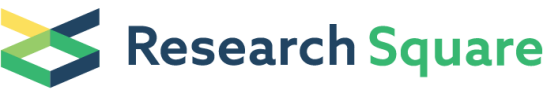 \\ Preprints are preliminary reports that have not undergone peer review. \\ They should not be considered conclusive, used to inform clinical practice, or referenced by the media as validated information.
}

\section{Thoracic blockade in percutaneous hepatocellular carcinoma.}

\section{Lidia Glinka}

Department of Anaesthesiology and Intensive Therapy, University of Warmia and Mazury in Olsztyn

\section{Małgorzata Braczkowska}

Department of Anaesthesiology and Intensive Therapy, University od Warmia and Mazury in Olsztyn

\section{Marek Kowalczyk}

Department of Labolatory Medicine, Faculty of Health Sciences, University of Warmia and Mazury in Olsztyn

\section{Łukasz Klepacki}

Department of Human Anatomy, University of Warmia and Mazury in Olsztyn

\section{Ewa Zieliński ( $\square$ ewa.zielinski.bydgoszcz@wp.pl)}

Department of Emergency Medicine and Disaster Collegium Medicum in Bydgoszcz Nicolaus Copernicus University in Toruń, Poland https://orcid.org/0000-0002-0013-6448

\section{Krzysztof Batia}

General and Oncological Surgery Clinic University Clinical Hospital in Olsztyn

\section{Karolina Osowiecka}

Department of Public Health. University of Warmia and Mazury in Olsztyn

\section{Łukasz Dyśko}

Department of General, Minimally Invasive and Elderly Surgery, University of Warmia and Mazury in Olsztyn

\section{Maciej Iwanowski}

II Clinic of Anaesthesiology and Intensive Care, University Clinical Hospital in Olsztyn

\section{Research article}

Keywords: hepatocellular carcinoma, percutaneous radiofrequency ablation, regional anaesthesia, thoracic paravertebral block

Posted Date: April 21st, 2020

DOl: https://doi.org/10.21203/rs.3.rs-23404/v1

License: (c) (1) This work is licensed under a Creative Commons Attribution 4.0 International License. Read Full License 


\section{Abstract}

Background Hepatocellular carcinoma (HCC) is a primary liver tumor that generally develops in a marshaltered liver. Local ablation using radio frequency waves is the first-line treatment for patients with early onset of this cancer who cannot undergo radical surgery. This is a painful procedure and must be performed under deep intravenous analgosedation or general anesthesia. The method that appears to meet the anesthesiological and surgical requirements is thoracic paravertebral block.

Aim of the study The main purpose of the study was to determine the efficacy and safety of paravertebral block compared to local perioperative anesthesia in patients who had percutaneous thermoablation as a treatment for $\mathrm{HHC}$.

Methods 30 patients enrolled in the treatment of hepatocellular carcinoma by percutaneous thermoablation were enrolled in the study. Two groups of patients were compared: group PVB - patients under paravertebral block anesthesia, group BB - patients under local anesthesia, without paravertebral block.

Results The use of paravertebral blockade (PVB) did not significantly reduce the patient's concerns about the postoperative period, the ability to ask questions to the doctor, receive understandable information about anesthesia, reduce stress levels or increase the level of satisfaction with pain therapy in the postoperative period ( $p>0.05$ ). Patients significantly more often experienced pain during surgery without paravertebral block $(p<0.001)$. Side effects of anesthesia occurred in both compared groups. They mainly concerned nausea and vomiting, which significantly more often occurred in the group without blockade (BB) and affected up to $60 \%$ of the respondents $(p=0.008)$. Significantly more often any painkillers were used among BB patients compared to PVB, respectively: immediately after surgery $53 \%$ vs $13 \%(p=0.02), 1$ hour after surgery $80 \%$ vs $27 \%(p=0.003)$, 3h after surgery $80 \%$ vs $14 \%(p<0.001)$, 6 h after surgery $60 \%$ vs $14 \%(p=0.008)$, after 24 h $47 \%$ vs $20 \%(p=0.12)$.

Conclusions The paravertebral block has proved to be a safe and well-tolerated and effective method of treating postoperative pain in patients with liver cancer treated by percutaneous thermoablation. Patients with PVB during the surgery and in the postoperative period had significantly less pain than in the control group.

Trial Registration: NCT04241887 from January 27, 2020

\section{Background}

Hepatic cell carcinoma (HCC, hepatocellular carcinoma), is the primary tumor of the liver generally developing on the substrate of cirrhosis. It accounts for $85-90 \%$ of all primary liver tumors. It is the fifth most malignant tumor in men and women in the world and is the third cause of death in the world among malignant tumors [1]. 
Local radio frequency ablation (RFA) is the first-choice treatment for patients with early HCC stage BCLC0 or BCLC-A in the BCLC (Barcelona Clinic Liver Cancer) classification, who cannot be undergoing radical surgery [2].

Thermoablation methods use a high temperature with radio frequency waves causing necrosis of tumor cells. The energy generated by the generator is transmitted through the needle with an ultrasound control into the mass of the tumor and causes its coagglomerating necrosis to arise around the tumor "safety zone", within which may become necrotic invisible in the ultrasound of the satellite nodules. Raising the temperature in the tumor mass to 55 degrees Celsius causes apoptosis of cells in a few seconds, immediately at 60 degrees Celsius.

$10-15 \%$ HCC is difficult or inaccessible to RFA and can be treated with other methods such as (PEI, percutaneous ethanol injection). The RFA is a very painful procedure and must be performed in deep intravenous anaesthesia or general anaesthesia $[3,4,5]$.

Regional anesthesia (RA), in comparison with general anaesthesia, enables verbal contact with the sick to be maintained, allowing cooperation with the surgeon and improving operating conditions. At present, the number of studies on the use of RA techniques for minimally invasive hepatological treatments is low. At present, the preferred method of anaesthesia is general anaesthesia or a combination of anesthetification with local anaesthesia. Anaesthesia should provide a complete lack of pain during surgery, unfortunately patients sometimes experience pain. Additionally, most patients experience severe pain for a few days or weeks after surgery, so it is important to understand the factors influencing these ailments and the availability of optimal anaesthesia $[6,7,8]$. RA application avoids complications and risks of general anaesthesia. The length of the regional blockages also translates into effective pain relief during the postoperative period.

The method that seems to meet the anaesthetic and surgical requirements is the Thoracic ParaVertebral Block (TPVB). It is one of the oldest techniques of regional anaesthesiology, described by the German gynecologist Hugo Selheim in 1905. The idea of TPVB is the administration of a topical anesthesia drug within the spinal area and the blockage of thoracic spinal nerves immediately after their exit through the intervertebral holes $[9,10]$. The location of the spinal space can be performed traditionally by anatomically based points or by using ultrasonography as a visualization technique. Since the use of only TPVB seemed to be an inadequate method of anaesthesia for such a painful procedure as the thermoablation of the liver, we decided to combine it with the shallow analgosedation.

\section{Objective of the study}

The main objective of the study was to determine the effectiveness and safety of the use of T PBV compared to topical anaesthesia in the perioperative period in patients who were treated with percutaneous thermoablation (PRFA) in the treatment of HCC. 


\section{Methods}

The study was prospective. After receiving the approval of the Bioethics Commission at the University of Warmia and Mazuria (Resolution No 46/2017 of 9.11.2017) and the consent of patients to participate in the study, 30 patients enrolled in HCC by Percutaneous Thermoablation were enrolled in the study.

Patients were randomly assigned to two groups. The criterion for inclusion in the study is: age of patients $>18$ years $<85$ years, primary tumor, admission to hospital in scheduled mode, single tumor $<5 \mathrm{~cm}$ in diameter or two tumors $<3 \mathrm{~cm}$ in diameter.

The criterion of disqualification of participation in the study is: mental illness, chronic pain, daily use of painkillers, ASA IV and V, thrombocytopenia ( $40 \times 10^{\wedge}$ 9/L), a significant degree of cirrhosis (Child-Pugh classification C).

Two groups of patients were compared:

- PVB Group - Patients with anahepatic blockade.

- Group BB - Patients with locally anaesthetics, without a spinal blockage.

The day before the procedure, each patient was instructed to use the NRS scale to assess the pain in the course of the blockage, during the surgical procedure and in the postoperative period (NRS 0: pain-free, NRS 10: the worst pain).

Preparation of the patient for anaesthesia was conducted in a standard manner, during an anaesthesiology visit on the eve of surgery. Premedication was not recommended. Patients were classified in terms of operational risk based on the ASA scale. On the day of the treatment after the assumption of standard intravenous access, patients were connected with a crystalloid infusion (Optilyte, Fresenius) $500 \mathrm{ml}$. Basal angesis was Paracetamol (Paracetamol, Kabi) $1.0 \mathrm{G} \mathrm{IV}$. As a rescue, bolus remifentanyl (Ultiva, GlaxoSmithKline) $1 \mathrm{mcg}$ kg. M. C -1 was administered for $>6$ pts in NRS.

Hypotension, defined as systolic blood pressure (SBP) $>30 \%$ of the initial value, was treated with intravenous fluid therapy and ephedrine $(5 \mathrm{mg})$ IV, bradycardia defined as heart rate $<50 / \mathrm{min}$ was treated with atropin. All patients used passive oxygen therapy for facial mask $(4-6 \mathrm{~L} / \mathrm{min})$ to maintain arterial oxygen saturation (SpO2, oxygen saturation) $>/=96 \%$.

\section{PVB technology}

PVB was performed by a major investigator, a specialist in anaesthesiology and intensive care and a qualified specialist in regional anaesthesia and treatment of acute pain. The procedure was performed under aseptic conditions in the pre-operative room, approx. $30 \mathrm{~min}$. before the planned operative procedure. 
Anesthesia was performed in the position on the left side, under USG control (ultrasonography). After laying the patient, the spineline of the vertebral body 8 was localized. Then, after disinfection of the skin (Kodan, Tinktur Forte, Schulke), a linear head (in a sterile manner) was applied, in the longitudinal plane, a few $\mathrm{cm}$ laterally in relation to the median line. The head was moved to the middle until the shadows of the two adjacent cross-sections and the pleural line between them were visible. Under aseptic conditions, the skin and subcutaneous tissue were infiltration with $2 \mathrm{ml}$ of $1 \%$ lignocaine (1\%hydrochlorite, WZF). Tuohy $22 \mathrm{~g}$ Needle (Smith Medical), introduced in-plane technique in real time from the tail side. After piercing the upper rib-transic ligament, with the tip of the needle in the vertebral space, after a negative aspiration (blood and/or cerebrospinal fluid), $20 \mathrm{ml}$ of $0.25 \%$ of bupivacaine was administered (Bupivacainum hydrochloricum wzf 0,5\%, Polfa Warszawa S.A.) Obtaining an image of the characteristic displacement of the pleural line by the volume of the Bipivacuaine solution administered. After each lock, adjacent spaces were scanned to assess the distribution of the drug and pleural motion to rule out possible complications (pleural). The patient was then laid on the back by continuing to monitor. The patient determined the degree of pain perception in the NRS during the procedure. Any complications during PTVB (nausea, vomiting, hemodynamic disturbances), were immediately treated and monitored. The range of anaesthesia in the target Dermatomes was determined 10 and 20 minutes after the lock was performed. After confirming the appropriate range of blockade, both groups used a shallow sedation with the use of propofol (propoph1\% Fresenius), and in the group with no blockage in addition to the use of remifentanyl $(0,02-0,25 \mathrm{mcg} / \mathrm{kg} / \mathrm{min})$. In both groups, the infusion was used at a variable rate to obtain and maintain a second or third level of sedation depth, rated at the Ramsey scale between 2 and 3 , (RSS-ramie Sedation Scale: 2-patient cooperating, oriented, CALM, RRS 3-sleepy patient, fulfilling the instructions) [11]. The Base Angesion was 1, $0 \mathrm{~g} \mathrm{IV} \mathrm{paracetamol.} \mathrm{The} \mathrm{bolus} \mathrm{of} \mathrm{remifentanyl,} 1 \mathrm{mcg} \mathrm{kg.} \mathrm{M.}$ $\mathrm{C}-1$, was administered as rescue angesion in the case of $>6 \mathrm{pts}$ in the NRS.

After the procedure, the satisfaction of the patient and the surgeon from the treatment conditions was assessed. After the treatment was discontinued, patients were transferred to the post-operative surveillance room in order to continue monitoring and clinical evaluation. The duration of the blockade was also observed, and the use of pain medication was monitored. For the treatment of pain in the postoperative room, patients were given non-opioid pain medication, weak or strong opioids, depending on the severity of the pain: NRS 1-4-Non-opioid drugs: Paracetamol, Metamizole (Metamizole, Kabi), NRS 4-6tramadol (Poltram, Polpharma), NRS > 6-Morphine (Morphini Sulfas WZF, Polfa Warszawa). The patient's satisfaction with the Anaesthesiology Technique (poll) was evaluated before the patient's exit from the hospital. The main investigator visited patients $24 \mathrm{~h}$ after the procedure, assessed pain in the wound/puncture area of the needle (surgical), patient satisfaction and possible complications.

\section{Percutaneous thermoablation technique}

For thermoablation treatments a needle of RF Medical Co. LTD, Needle-BT 2030 is used. The needle was inserted into the tumor under ULTRASOUND control in each case. The thermoablation of the outbreak was performed in a 12-minute cycle with a power range of up to $200 \mathrm{~W}$, the minimum temperature of 
thermoablation above 60 degrees Celsius. The needle cooling system was closed, based on the use of saline for cooling ( $0.9 \%$ Natrium chloratum). RF Medical Generator V-1000 was used.

The end of the needle is equipped with a temperature sensor, whereby the temperature inside the tumor has been measured after the thermoablation cycle, within a range of $30 \mathrm{~mm}$ from the needle. When the temperature of $65^{\circ} \mathrm{C}$ or more was reached, the treatment was considered to be residual. At the exit of the tumour needle after the end of the thermoablation cycle, a generator was activated to be denatated by the output needle to preserve the "oncological purity" and to perform the appropriate hemostasis. The patient's cooperation is very important in the HCC outbreaks located in segments 1, 7, 8 of the liver. In order to gain access to these tumours, it was necessary to bypass the pleural carefully and obtain an elevation of the diaphragm in order to properly insert the needle into the central tumour field. In such cases, good contact and cooperation with the sick is necessary. The sick by taking and stopping the breath had to adjust the location of the diaphragm, and the same pleural, so that it is safe to enter and properly locate the needle for thermoablation. In such cases, the patient before Anhypodic had the anahepatic skin and the potential channel of the needle pass through the intercostor. A solution of $0.5 \%$ lignocaine in the amount of $5 \mathrm{ml}$ (Lignocainum hydrochlorytes, WZF 1\%) was used for anaesthesia. The 2-3 mm incision was then performed, by which the needle was inserted into the thermoablation. If the treatment did not require contact with the sick incision of the skin was not performed and the needle was injected directly through the puncture of the skin. During the treatment of thermoablation, the patient lay on the back, in the case of HCC tumors located in the Segment 1, 7, 8 of the liver with the end of the limb upper right approx. 120-140 degrees.

At the time of the study, the Surgeon's satisfaction with the proposed anaesthesia was assessed in both groups according to the survey. Another evaluated parameter was the satisfaction of patients with anaesthesia also according to the survey. The degree of pain perception in both groups of patients was also evaluated at the following time points on the NRS scale: at the time of anaesthesia, during the exercise of thermoablation, immediately after surgery, in 1-3-6-24 hours after PTRFA. The consumption of pain medication in both groups of patients was monitored at the same time points. Additionally, the total duration of the procedure, the range of anaesthesia in patients with PVB, the duration of PVB, the side effects of both anaesthesia techniques were evaluated.

\section{Statistical analysis}

In order to compare 2 independent quantitative tests, the student's T-Test (age) was used because the distribution of variables measured using the Shapiro-wolf test was similar to normal $(P>0.05)$. For comparison, 2 Independent order attempts were performed by the Mann-Whitney Test. The Chi2 Test was applied to compare the proportions in the subgroups. The level of statistical significance was $p<0.05$. Statistical analyses were conducted using STATISTICA 13.1 (Statsoft, Poland).

\section{Results}

\section{Characteristics of the groups tested}


A total of 30 patients were enrolled in the study, averaging 63 years of age, half of which were females. Half of the subjects had a secondary education and lived in Cities $>50$ thousand of residents. The groups examined were not statistically different in age, gender, BMI of residence or education $(P>0.05)$. All patients were in the ASA 1-3 classification. Blood clotting parameters were normal in all patients (Table 1).

\section{Location and size of the HCC in the liver}

The size of the tumour ranged from 0.6 to $4 \mathrm{~cm}$ (average $2.11 \pm 0.8 \mathrm{~cm}$ ). The majority of liver lesions were single outbreaks in the 6-8 segment (Fig. 1.2). There were no significant differences in the location and size of tumours between patients in the PVB group and patients with topical anaesthetics.

Execution of the blockade extended the waiting time for surgery to start, which had a significant impact on its assessment $(8.13 \vee 9.8)$. Despite the inconvenience of prolonged waiting for surgery, surgeons have better appreciated the PVB group. Overall: Cooperation with the patient in terms of communication, location of changes in needle handling, movement - were significantly better in the PVB group.

The level of anaesthesiology satisfaction assessment was comparable between the two groups (approximately 9, $\mathrm{p}=0.76$ ) (Table 2 ).

The use of the blockade did not significantly affect the patient's concern about the postoperative period, the possibility of asking questions to the physician, obtaining understandable information on anaesthesia, lowering stress levels or increasing the level of satisfaction with pain therapy during the postoperative period $(P>0.05)$. There was a significant incidence of painful discomfort during the surgical procedure IN patients with BB $(P<0.001)$ (Table 3$)$.

NRS (SD-) (Numerical Rating Scale) in the course of PVB was 1, 07 (0.8), in patients with BB-0.27 (0.59). During the surgical procedure, significantly lower pain intensity was observed in the PVB group: NRS 1.27 (1.58). In group BB, the mean NRS was 3.73 (2.37). 4 patients felt discomfort during the performance of the PVB and 5 patients with PVB were experiencing pain during surgery. In the non-blockade group, 11 patients experienced pain from 2-8 in the NRS, but they were rapidly alleviated, resulting in a positive assessment of this anaesthesia. Immediately after surgery, the pain in the PVB group did not exceed 4 points on the NRS scale, while in the BB group it ranged from 0-10 (1.1 versus 2.8). The biggest pain in the BB group was 1 hour. After treatment (NRS 6.2), then these ailments were reduced until almost complete resolution after 24 hours. Overall, they were significantly greater than those in the PVB group (Fig. 3.).

The highest consumption of pain medication was related to group BB, especially in the immediate postoperative period and in 1-3 -6 hours. After the procedure. This was mainly due to strong opioids. $7 \%$ of patients in this group required strong opioids for 24 hours. After the operation. Significantly more frequently, any pain medication was used among BB patients compared to PVB respectively: immediately after the procedure $53 \%$ vs $13 \%(P=0.02), 1 \mathrm{~h}$ after the procedure $80 \%$ vs. $27 \%(P=0.003), 3 \mathrm{~h}$ after treatment $80 \%$ vs $14 \%(P<0.001), 6$ h after surgery $60 \%$ vs $14 \%(P=0.008)$, after 24 h $47 \%$ vs $20 \%(P=$ 
0.12). There were no significant differences between the consumption of strong and weak opioid drugs directly, 1 h, 3, 6, 24 h after surgery $(P>0.05)$ (Table 4, Fig. 4-8).

Bilateral blockade incidents were not observed. In most cases, the range of PVB anaesthesia dermatomes ranged from T6 to T11/12. The mean duration of PVB retention was 7 hours. Hemodynamic parameters remained stable in both groups of patients during and after the surgical procedure.

Adverse reactions of anaesthesia occurred in both groups compared. They mainly concerned nausea and vomiting, which were significantly more common in the BB group and concerned as much as $60 \%$ of subjects $(p=0.008)$ (Fig. 8).

\section{Discussion}

Our study found that PVB in Percutaneous HCC thermoablation is an effective, safe and well-evaluated technique for patients and surgeons.

Despite an increase in the total waiting time for anaesthesia, the impact on surgeons' satisfaction was between the years and the postoperative period, in which they significantly better evaluated the working conditions of the PVB group.

The average duration of the PVB was $15 \mathrm{~min}$. and the duration of the blockade- $18 \mathrm{~min}$. Piccioni et al. Performed PVB in 6.5 minutes using the peripheral nerve stimulator. Anesthesia occurred in this case after 15-20 min, using $0.5 \%$ levobupivacaine [12]. The level of sympathetic blockade was sufficient to carry out the procedure on average after $25 \mathrm{~min}$. Most authors give a range of 15-30 min. [13.14], which may arise from the experience of anaesthesiologist performing PVB and used imaging technique, and anesthetic drug. In our case, all patients were visualized using ULTRASOUND. Shorter blockage time was obtained by cHeung Ning and M Karmakar, studying a group of 20 patients. They used ropivacaine $0.75 \%$ by obtaining a sensory lock after $10 \mathrm{~min}$. from the implementation of PVB [10]. Mohamed et al. Obtained anation after $10 \mathrm{~min}$. from the performance of PVB using as in our case $0,5 \%$ bupivacaine, but in a volume of $25 \mathrm{ml}$ [15]. Summing up the duration of the blockade and the achievement of the appropriate level of anaesthesia, it appears to be adversely affected by the operational efficiency of the operation block, however, the benefits of perioperative conditions prevail in the assessment of surgeons and patients.

Surgeons have better appreciated the operating conditions in the PVB group. They particularly stressed that in this group the sick better cooperated during the whole procedure. Reduced pain in the case of PVB allowed for the reduction of analgosedation to a minimum, which significantly improved verbal contact with patients. Similar results were achieved by Gazzera et al. In 30 individuals, where 33, 3\% of patients reported moderate pain during ablation by requiring additional intravenous sedation [16]. A description of 12 PVB cases can also be found in the literature without the need for additional analgosedation during the procedure [12]. 
PRV may cause shoulder pain due to irritation of the diaphragm nerve [17.18]. The use of shallow analgosedation in conjunction with regional or local anaesthesia seems to prevent this complication. In our work we did not observe this complication in any of the groups tested.

Most patients had a positive assessment of PVB, despite experiencing significantly greater discomfort at the time of exercise than in the non-blocking group. Interestingly, when comparing both groups, the level of patient satisfaction in both groups was similar.

During the postoperative period, the benefits of PVB significantly exceeded the disadvantages associated with its implementation. Patients in the PVB group felt much less pain than the control group. NRS at individual time points in no patients exceeded 5 points, reflecting the consumption of painkillers. In patients from the BB group, the strongest pain occurred in 1-3 hours after thermoablation, with a peak at 1 hour, in which the pain was assessed on an average of 6.2 points. This resulted in the quantity and quality of pain killers used. The patients in this group were required opioid drugs by most. In 24 hours after the treatment in group BB the pain was defined in the range $0-5$, while in the PVB group $0-3$.

When it comes to side effects, these include nausea and vomiting. The higher consumption of opioids in group BB influenced the increased incidence of post-operative nausea and vomiting, and probably painrelated discomfort also contributed to this. We did not observe the reflex vasovagal reaction in our patients after the performance of PVB.

In the literature, in the case of HCC thermoablation, a comparison of the PVB to epidural anaesthesia is often encountered. Data indicate that in the case of PVB there is a lower percentage of urine retention, postoperative nausea and vomiting and hypotension [19].

From a comparison of PVB to general anaesthesia, it is also apparent that, in the first case, hemodynamic stability, post-operative pain control and less nausea and vomiting are better $[12,20]$.

The interesting work was published by Renchun et al. In 2012, analysing the effect of the type of anaesthesia on the incidence of tumour recurrence and the survival time of patients with HCC. It has been found that the type of anaesthesia has no effect on the survival of patients, but general anaesthesia is associated with a higher incidence of tumour recurrence [21]. For similar applications came Yuang-Hung et al. by examining 118 patients [22].

Therefore, the choice of anaesthesia technique should take into account a whole range of factors and individualise the procedure depending on the specific case.

\section{Conclusions}

PBV has been found to be safe and well-tolerated by patients and an effective method of treating postoperative pain in HCC patients treated with PRFA. 
Patients with PVB during surgery and in the postoperative period had significantly lower pain symptoms than in the control group.

\section{Abbreviations}

BCLC - Barcelona Clinic Liver Cancer,

HCC - Hepatocellular Carcinoma - hepatocellular carcinoma

PEI - Percutaneous Ethanol Injection - percutaneous ethanol injection

RA - Regional Anaesthesia - regional anesthesia

RFA - Radiofrrequency Ablation - ablation using radio frequency waves

PRFA - Percutaneus Radiofrrequency Ablation - transcutaneous ablation using radio frequency waves SBP - Systolic Blood Pressure

Sp02 - Oxygen Saturation - oxygen saturation of arterial blood

TPVB - Thoracic ParaVertebral Block - chest block

\section{Declarations}

Ethics Approval and Consent to Participate - all patients gave written consent for participation, in addition, Consent of the Bioethics Committee: Resolution No. 46/2017 of 9/11/2017 issued by the Bioethics Committee at the University of Warmia and Mazury in Olsztyn, Poland.

Consent to publication - Not applicable.

Availability of data and supporting materials section - Data are in additional supporting file, for more materials please contact author for data requests.

Competing Interests - The authors declare that they have no competing interests.

Funding - Not applicable.

Acnowledgments - Not applicable.

\section{Author's contributions}

LG - collecting clinical materials; clinical material analysis; substantive supervision; methodological supervision; statistical study; review of scientific literature 
MB - collecting clinical materials; clinical material analysis; substantive supervision; methodological supervision; statistical study; review of scientific literature

MK - collecting clinical materials; clinical material analysis; substantive supervision; methodological supervision; statistical study; review of scientific literature

$Ł K$ - statistical study; review of scientific literature

EZ - review of scientific literature; statistical study, clinical material analysis; development of a clinical material; adaptation of the article to editorial requirements

KB - clinical material analysis, review of scientific literature

KO - clinical material analysis, review of scientific literature

$Ł D$ - clinical material analysis, review of scientific literature

MI - clinical material analysis, review of scientific literature

All authors have given their written consent for publication. All authors read and approved the final manuscript.

\section{References}

1. Aysegul Ozakyol. Global Epidemiology of Hepatocellular Carcinoma (HCC Epidemiology) J Gastrointest Cancer. 2017 Jun 19. doi: 10.1007/s12029-017-9959-0.

2. Krawczyk, M. Wasilewicz, M. Hartleb et al. Diagnosis and treatment of hepatocellular carcinoma recommendations of Hepatological Group of Polish Society of Gastroenterology. Gastroenterologia Kliniczna 2015, tom 7, nr 3, 65-89.

3. H. Hung, Y.Y. Chiou, C.Y. Hsia, C.W. Su, Y.H. Chou, J.H. Chiang, et al. Survival rates are comparable after radiofrequency ablation or surgery in patients with small hepatocellular carcinomas Clin Gastroenterol Hepatol, 9 (2011), pp. 79-86

4. Zhou, Y. Zhao, B. Li, D. Xu, Z. Yin, F. Xie, et al. Meta-analysis of radiofrequency ablation versus hepatic resection for small hepatocellular carcinoma BMC Gastroenterology, 10 (2010), pp. 78-84

5. K. Cho, J.K. Kim, M.Y. Kim, H. Rhim, J.K. Han Systemic review of randomized trials for hepatocellular carcinoma treated with percutaneous ablation therapies Hepatology, 49 (2009), pp. 453-459

6. Sanghee L, Hyunchul R., Young-Sun K., et all. Percutaneus radiofrequency ablation of hepatocellular carcinomas: factors related to intraprocedural and postprocedural pain.AJR:192, 2009;1064-1070.

7. Tateishi, S. Shiina, T. Teratani, S. Obi, S. Sato, Y. Koike, et al. Percutaneous radiofrequency ablation for hepatocellular carcinoma. An analysis of 1000 cases Cancer, 103 (2005), pp. 1201-1209

8. C. Wu, Y.H. Huang, G.Y. Chau, C.W. Su, C.R. Lai, P.C. Lee, et al. Risk factors for early and late recurrence in hepatitis B-related hepatocellular carcinoma J Hepatol, 51 (2009), pp. 890-897 
9. Hexiang Chen, MMSc, Zhipin Liao,et all. Continuous Right Thoracic Paravertebral Block Following Bolus Initiation Reduced Postoperative Pain After Right-Lobe Hepatectomy. Reg Anesth Pain Med. 2014 Nov; 39(6): 506-512.

10. Cheung Ning M, Karmakar MK (2011) Right thoracic paravertebral anaesthesia for percutaneous radiofrequency ablation of liver tumours. $\mathrm{Br} \mathrm{J}$ Radiol 84:785-789.

11. Ramsay MAE, Savege TM, Simpson BRJ, Goodwin R. Controlled sedation with alphaxalonealphadolone. Br Med J 1974;2:656-9.

12. Piccioni F, Fumagalli L, Garbagnati F, Di Tolla G, Mazzaferro V, Langer M. Thoracic paravertebral anesthesia for percutaneous radiofrequency ablation of hepatic tumors. J Clin Anesth. 2014;26:2715.

13. Hura G, Knapik P, Misiołek H, Krakus A, Karpe J. Sensory blockade after thoracic paravertebral injection of ropivacaine or bupivacaine. Eur J Anaesthesiol 2006;23:658-64 [PubMed] [Google Scholar]

14. Klein SM, Greengrass RA, Weltz C, Warner DS. Paravertebral somatic nerve block for outpatient inguinal herniorrhaphy: an expanded case report of 22 patients. Reg Anesth Pain Med 1998;23:30610.

15. Mohamed M. Abu Elyazed and Mohammad A. Abdullah. Thoracic paravertebral block for the anesthetic management of percutaneous radiofrequency ablation of liver tumors. J Anaesthesiol Clin Pharmacol. 2018 Apr-Jun; 34(2): 166-171.

16. Carlo Gazzera, Paolo Fonio, Riccardo Faletti et all. Role of paravertebral block anaesthesia during percutaneous transhepatic thermoablation. Radiol Med.(2014)119:549-557.

17. Head HW, Dodd GD, 3rd, Dalrymple NC, Prasad SR, El-Merhi FM, Freckleton MW, et al. Percutaneous radiofrequency ablation of hepatic tumors against the diaphragm: frequency of diaphragmatic injury. Radiology 2007;243:877-84.

18. Baumgarten RK. Thoracic paravertebral block: is single injection really safer? Reg Anesth Pain Med 2006;31:584.

19. Davies RG1, Myles PS, Graham JM. A comparison of the analgesic efficacy and side-effects of paravertebral vs epidural blockade for thoracotomy-a systematic review and meta-analysis of randomized trials. Br J Anaesth. 2006 Apr;96(4):418-26.

20. K. Karmakar. Thoracic paravertebral block. Anesthesiology, 95 (2001), pp. 771-780.

21. Renchun Lai, Zhenwei Peng, Dongtai Chen et all. The Effects of Anesthetic Technique on Cancer Recurrence in Percutaneous Radiofrequency Ablation of Small Hepatocellular Carcinoma. Gastroenterol Nurs. 2011 Mar-Apr;34(2):129-34.

22. Yuan-Hung Kuo ,Kuan-Chih Chung , Chao-Hung Hung et all. The impact of general anesthesia on radiofrequency ablation of hepatocellular carcinoma. The Kaohsiung Journal of Medical Sciences. Volume 30, Issue 11, November 2014, Pages 559-565.

\section{Tables}


Table 1. Characteristics of the test group.

\begin{tabular}{|c|c|c|c|c|c|c|c|c|}
\hline & & \multicolumn{2}{|c|}{ EVERYBODY } & \multicolumn{2}{|c|}{ BLOCKADE } & \multicolumn{2}{|c|}{ NO BLOCKADE } & \multirow[b]{2}{*}{$p$} \\
\hline \multirow[t]{2}{*}{ Variables } & & $\mathrm{n}$ & $\%$ & $\mathrm{n}$ & $\%$ & $\mathrm{n}$ & $\%$ & \\
\hline & & 30 & 100 & 15 & 100 & 15 & 100 & \\
\hline Age & (range; average \pm ) & \multicolumn{2}{|c|}{ (48-82 lat; $62.9 \pm 8.4$ ) } & \multicolumn{2}{|c|}{ (50-76 lat; $62.3 \pm 8.4$ ) } & \multicolumn{2}{|c|}{ (48-82 lat; $63.5 \pm 8.6$ ) } & 0.72 \\
\hline BMI & (range; average \pm ) & \multicolumn{2}{|c|}{$(19.1-39.8 ; 26.1 \pm 4.6)$} & \multicolumn{2}{|c|}{$(19.1-30.99 ; 24.9 \pm 4.1)$} & \multicolumn{2}{|c|}{$(20.4-39.8 ; 27.2 \pm 5.0)$} & 0.29 \\
\hline \multirow[t]{3}{*}{ Sex } & & & & & & & & \multirow[t]{3}{*}{0.27} \\
\hline & woman & 15 & 50 & 9 & 60 & 6 & 40 & \\
\hline & men & 15 & 50 & 6 & 40 & 9 & 60 & \\
\hline \multirow[t]{4}{*}{ Education } & & & & & & & & \multirow[t]{4}{*}{0.56} \\
\hline & primary & 6 & 20 & 4 & 27 & 2 & 13 & \\
\hline & secondary & 16 & 53 & 8 & 53 & 8 & 53 & \\
\hline & higher & 8 & 27 & 3 & 20 & 5 & 33 & \\
\hline \multirow[t]{5}{*}{ Place of residence } & & & & & & & & \multirow[t]{5}{*}{0.86} \\
\hline & village & 2 & 7 & 1 & 7 & 1 & 7 & \\
\hline & City up to 10.000 residents & 5 & 17 & 2 & 13 & 3 & 20 & \\
\hline & City up to 50.000 residents & 8 & 27 & 5 & 33 & 3 & 20 & \\
\hline & City above 50.000 residents & 15 & 50 & 7 & 47 & 8 & 53 & \\
\hline
\end{tabular}

\section{Legend:}

BMI-Body Mass Index,

body mass factor,

n-Number of patients.

Table 2. Surgeon satisfaction. 


\begin{tabular}{|c|c|c|c|c|c|c|c|}
\hline & \multicolumn{3}{|c|}{ BLOCKADE $(n=15)$} & \multicolumn{3}{|c|}{ NO BLOCKADE $(\mathrm{n}=15)$} & \multirow[b]{2}{*}{$p$} \\
\hline & Range & Average & $\begin{array}{l}\text { Standard } \\
\text { deviation }\end{array}$ & Range & Average & $\begin{array}{l}\text { Standard } \\
\text { deviation }\end{array}$ & \\
\hline Did blocking by an anesthetist disturb the operation plan? & $5-10$ & 7,73 & 1,79 & - & - & - & - \\
\hline $\begin{array}{l}\text { How long did you have to wait for the procedure to start since the } \\
\text { blockade was made? }\end{array}$ & $5-10$ & 8,13 & 1,88 & - & - & - & - \\
\hline $\begin{array}{l}\text { How long did you have to wait for the operation to start since entering } \\
\text { the operating theater? }\end{array}$ & $5-10$ & 8,13 & 1,73 & $8-10$ & 9,80 & 0,56 & 0.003 \\
\hline Were you able to communicate with the patient satisfactorily? & $5-10$ & 9,20 & 1,52 & $1-10$ & 5,40 & 2,26 & $<0.001$ \\
\hline Did the patient cooperate during the lesion location? & $5-10$ & 8,87 & 1,88 & $1-9$ & 5,27 & 2,15 & $<0.001$ \\
\hline $\begin{array}{l}\text { Did the patient cooperate while guiding the needle towards the } \\
\text { change? }\end{array}$ & $5-10$ & 9,07 & 1,79 & $1-7$ & 4,07 & 1,75 & $<0.001$ \\
\hline Did the patient move during the procedure? & $5-10$ & 8,87 & 1,73 & $5-8$ & 7,00 & 1,00 & 0.001 \\
\hline $\begin{array}{l}\text { Are you satisfied with the operating conditions created by the } \\
\text { anesthesiologist? }\end{array}$ & $5-10$ & 9,40 & 1,40 & $3-8$ & 5,60 & 1,40 & $<0.001$ \\
\hline How would you rate anaesthesiological care? Scale 1-10 & $5-10$ & 8,73 & 1,75 & $5-10$ & 9,00 & 1,51 & 0.76 \\
\hline
\end{tabular}

\section{Legend:}

1 - means no satisfaction, 10 - max. satisfaction.

Table 3. Patient Satisfaction 


\begin{tabular}{|c|c|c|c|c|c|}
\hline & $\begin{array}{c}\text { n } \\
15\end{array}$ & $\begin{array}{c}\% \\
100\end{array}$ & $\begin{array}{c}\text { BLO } \\
n \\
15\end{array}$ & $\begin{array}{l}\mathrm{O} \\
\mathrm{KADE} \\
\% \\
100\end{array}$ & $p$ \\
\hline $\begin{array}{l}\text { During the interview with the anesthetist before the surgery: did your fears regarding the perioperative } \\
\text { period have decreased? }\end{array}$ & & & & & 0.13 \\
\hline YES & 12 & 80 & 15 & 100 & \\
\hline NO & 3 & 13 & 0 & 0 & \\
\hline During the interview with the anesthetist before the procedure: could you ask questions? & & & & & 0.31 \\
\hline YES & 15 & 100 & 14 & 93 & \\
\hline NO & 0 & 0 & 1 & 7 & \\
\hline $\begin{array}{l}\text { During the interview with the anesthesiologist before the procedure: were you given information about } \\
\text { anesthesia in an accessible and understandable way? }\end{array}$ & & & & & 0.31 \\
\hline YES & 15 & 100 & 14 & 93 & \\
\hline NO & 0 & 0 & 1 & 7 & \\
\hline $\begin{array}{l}\text { During the interview with the anesthesiologist before the surgery: did you provide information on the } \\
\text { postoperative period in an accessible and understandable way? }\end{array}$ & & & & & 0.31 \\
\hline YES & 15 & 100 & 14 & 93 & \\
\hline NO & 0 & 0 & 1 & 7 & \\
\hline After talking to the anaesthesiologist after the procedure, did you feel calmer and less stressed? & & & & & 0.36 \\
\hline YES & 11 & 73 & 13 & 87 & \\
\hline NO & 4 & 27 & 2 & 13 & \\
\hline Did you feel any pain or discomfort while performing regional anesthesia? & & & & & - \\
\hline YES & 4 & 27 & 0 & 0 & \\
\hline NO & 11 & 73 & 0 & 0 & \\
\hline NOT APPLICABLE & 0 & 0 & 15 & 100 & \\
\hline Did you feel any pain during the surgery? & & & & & $<0.001$ \\
\hline YES & 5 & 33 & 11 & 73 & \\
\hline NO & 10 & 67 & 4 & 27 & \\
\hline Are you satisfied with pain therapy in the postoperative period? & & & & & 0.20 \\
\hline YES & 13 & 87 & 10 & 67 & \\
\hline NO & 2 & 13 & 5 & 33 & \\
\hline Would you choose this type of anesthesia? & & & & & 1.00 \\
\hline YES & 12 & 80 & 12 & 80 & \\
\hline NO & 3 & 20 & 3 & 20 & \\
\hline Would you recommend anesthesia of this type to a loved one? & & & & & 1.00 \\
\hline YES & 12 & 80 & 12 & 80 & \\
\hline
\end{tabular}


Legend:

1 means no satisfaction,

10-maximum satisfaction.

Table 4. Consumption of pain medication.

\begin{tabular}{|c|c|c|c|c|c|}
\hline & \multicolumn{2}{|c|}{ BLOCKADE } & \multicolumn{2}{|c|}{ NO BLOCKADE } & \multirow{3}{*}{$p$} \\
\hline & $\mathbf{n}$ & $\%$ & $\mathbf{n}$ & $\%$ & \\
\hline & 15 & 100 & 15 & 100 & \\
\hline pain medication; immediately after the procedure & & & & & $0.02 *$ \\
\hline no medicine & 13 & 87 & 7 & 47 & \\
\hline Weak opioids & 1 & 6.5 & 5 & 33 & \\
\hline Strong opioids & 0 & 0 & 3 & 20 & \\
\hline Non-opioid drugs & 1 & 6.5 & 0 & 0 & \\
\hline pain medication; $1 \mathrm{~h}$ after surgery & & & & & $0.003^{*}$ \\
\hline no medicine & 11 & 73 & 3 & 20 & \\
\hline Weak opioids & 3 & 20 & 7 & 47 & \\
\hline Strong opioids & 0 & 0 & 5 & 33 & \\
\hline Non-opioid drugs & 1 & 7 & 0 & 0 & \\
\hline pain medication; $3 \mathrm{~h}$ after surgery & & & & & $<0.001 *$ \\
\hline no medicine & 13 & 86 & 3 & 20 & \\
\hline Weak opioids & 1 & 7 & 10 & 67 & \\
\hline Strong opioids & 0 & 0 & 2 & 13 & \\
\hline Non-opioid drugs & 1 & 7 & 0 & 0 & \\
\hline pain medication; $6 \mathrm{~h}$ after surgery & & & & & $0.008^{*}$ \\
\hline no medicine & 13 & 86 & 6 & 40 & \\
\hline Weak opioids & 1 & 7 & 7 & 47 & \\
\hline Strong opioids & 0 & 0 & 2 & 13 & \\
\hline Non-opioid drugs & 1 & 7 & 0 & 0 & \\
\hline pain medication; $24 \mathrm{~h}$ after surgery & & & & & $0.12 *$ \\
\hline no medicine & 12 & 80 & 8 & 53 & \\
\hline Weak opioids & 1 & 7 & 6 & 40 & \\
\hline Strong opioids & 0 & 0 & 1 & 7 & \\
\hline Non-opioid drugs & 2 & 13 & 0 & 0 & \\
\hline
\end{tabular}

*p-value comparing the group of patients did not use drugs vs the group of patients used any drugs (weak, strong opioids, non-opioid drugs) after surgery

\section{Figures}




\section{Localization of HCC tumors}

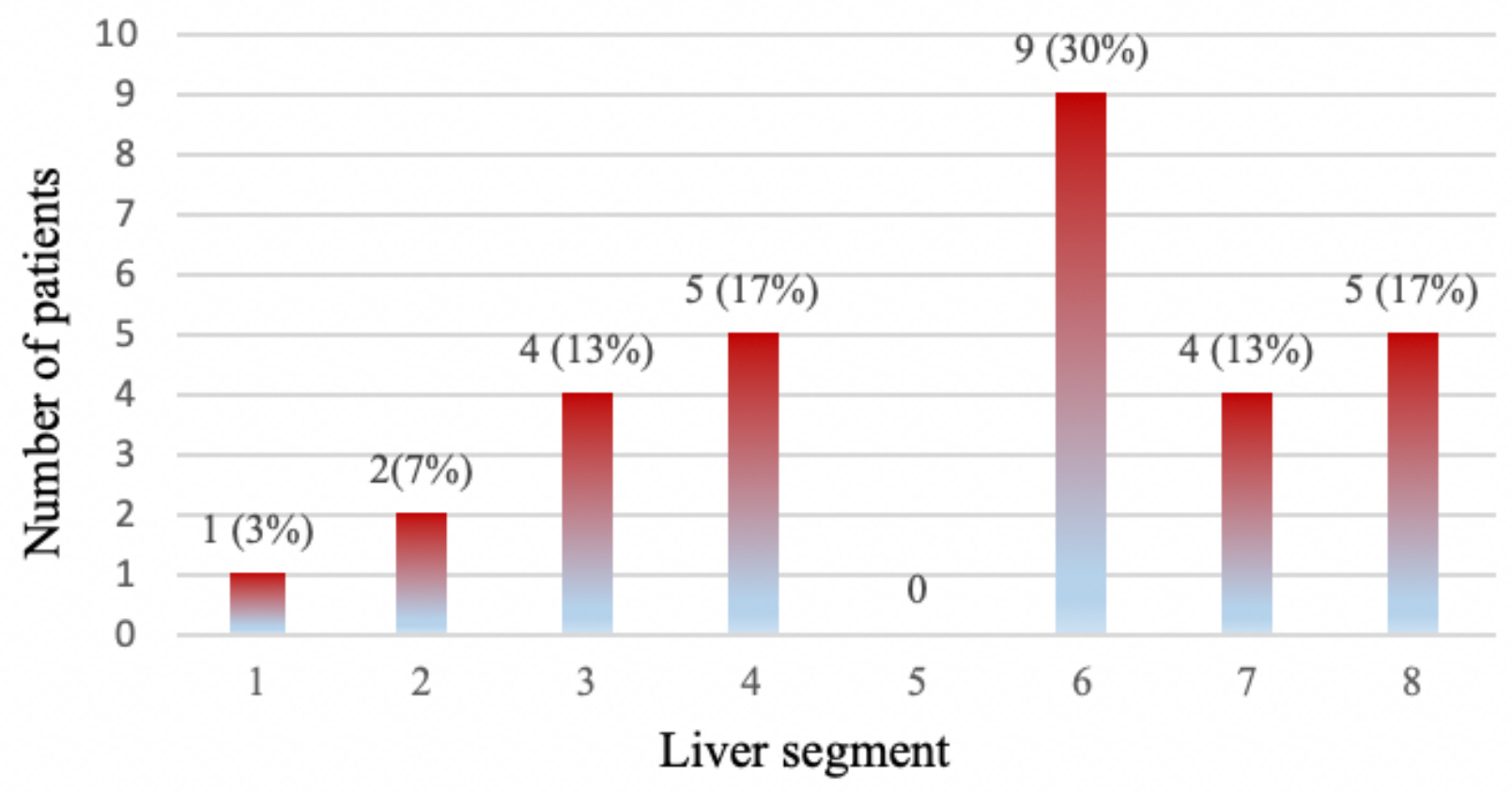

Figure 1

Tumour location. 


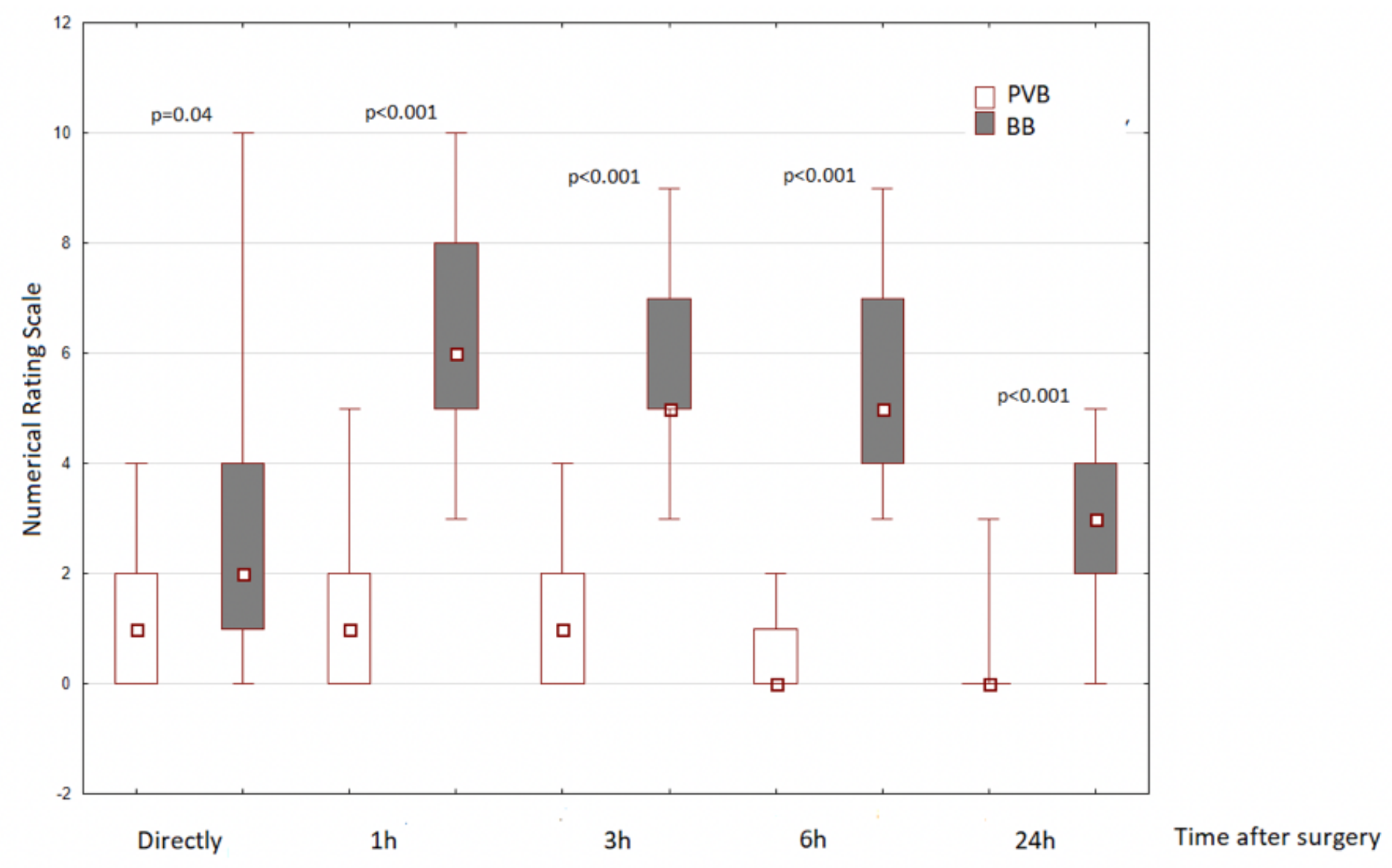

Figure 2

Pain intensity Scale during the first 24 hours Postoperative. Legend: NRS (0-10), where 0 is no pain, 10 the strongest pain. 


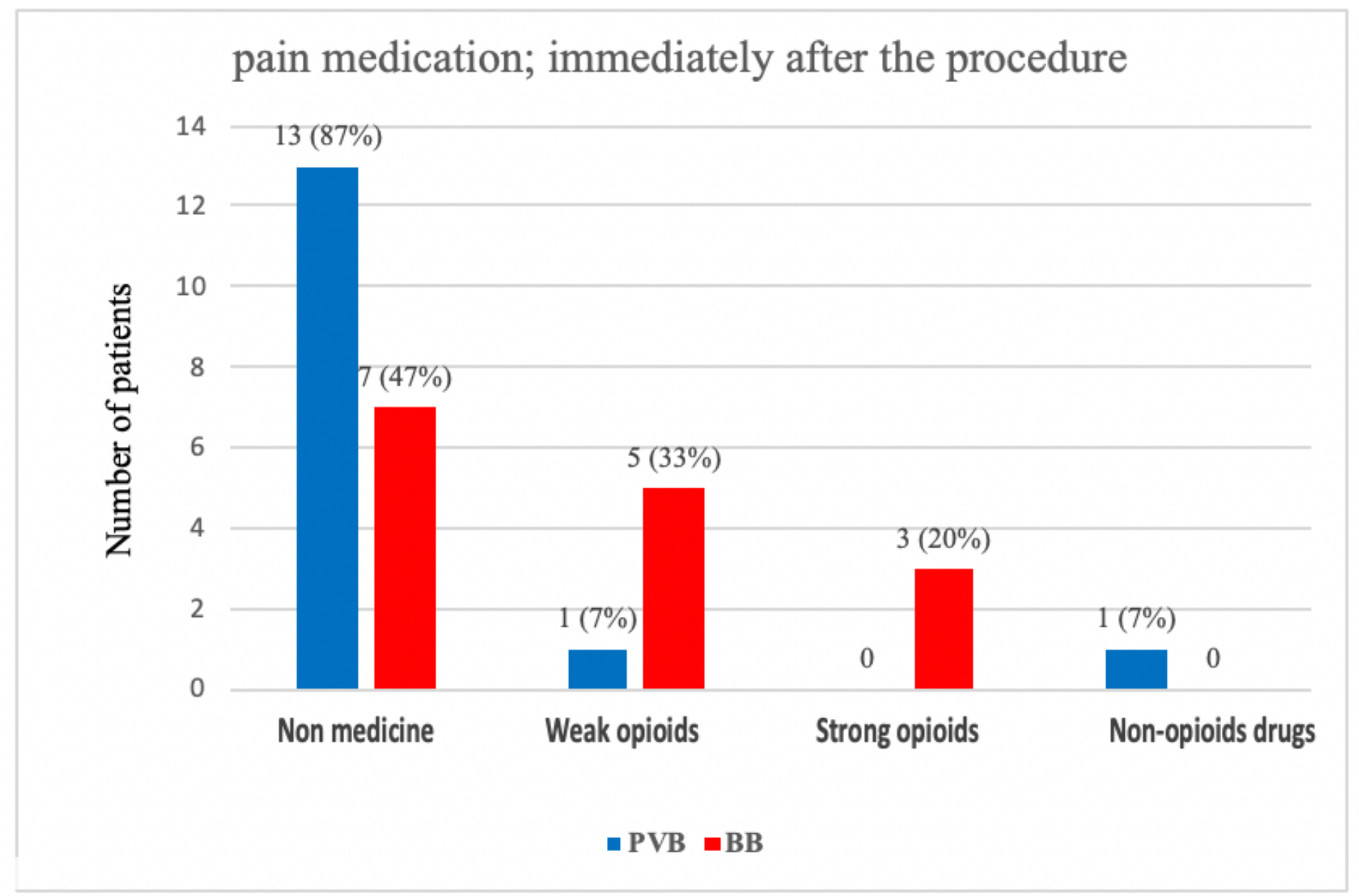

Figure 3

The Consumption of pain medication in the immediate postoperative period. 


\section{pain medication; $1 \mathrm{~h}$ after surgery}

12

$$
11(73 \%)
$$

10

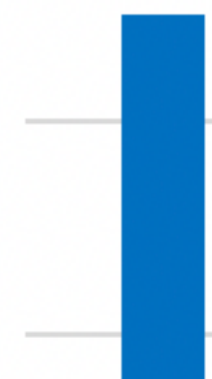

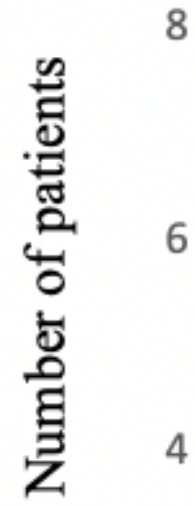

Figure 4

Pain medication Consumption 1 hour after surgery. 


\section{pain medication; $3 \mathrm{~h}$ after surgery}

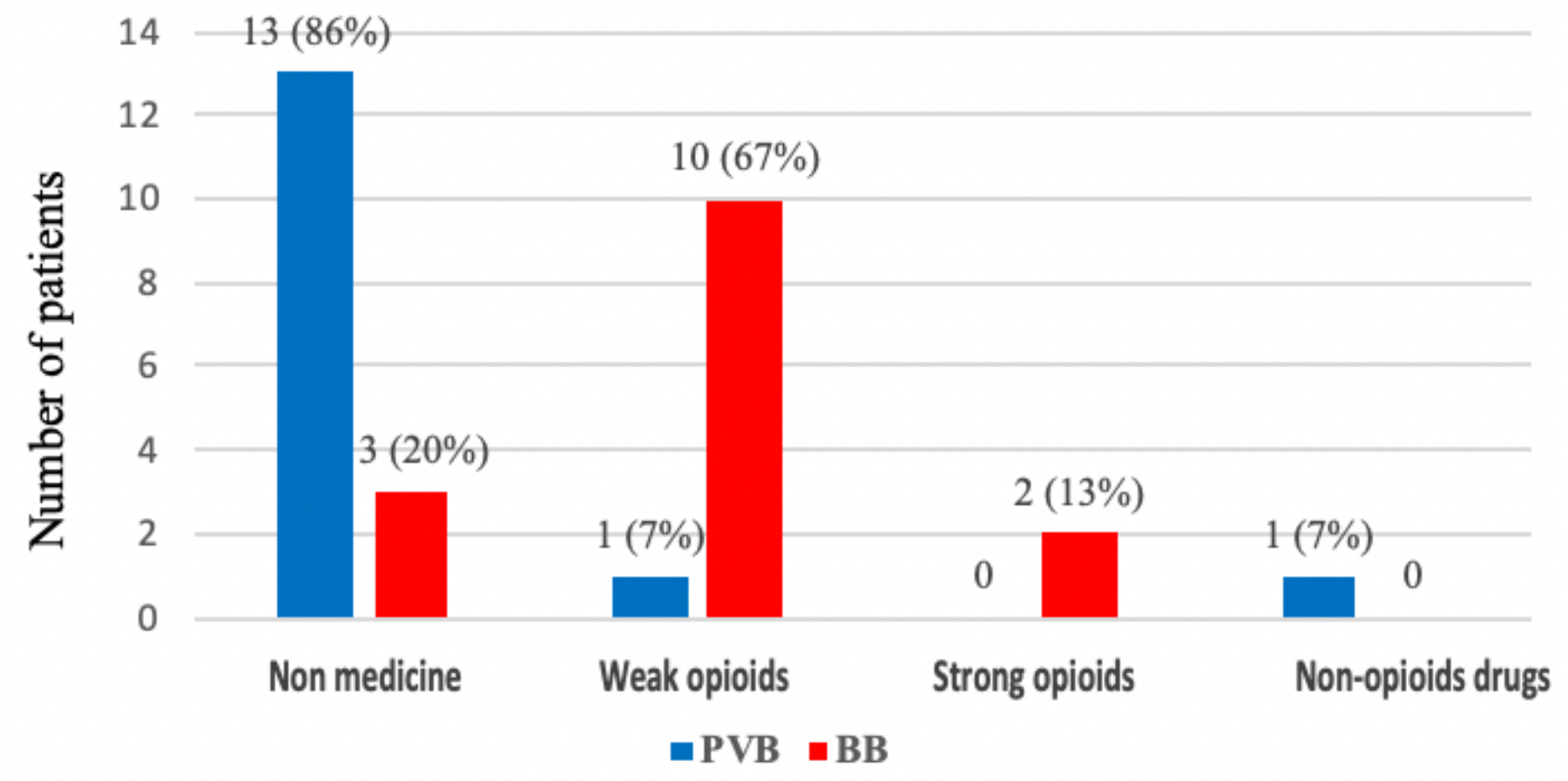

Figure 5

Pain medication Consumption 3 hours after surgery. 


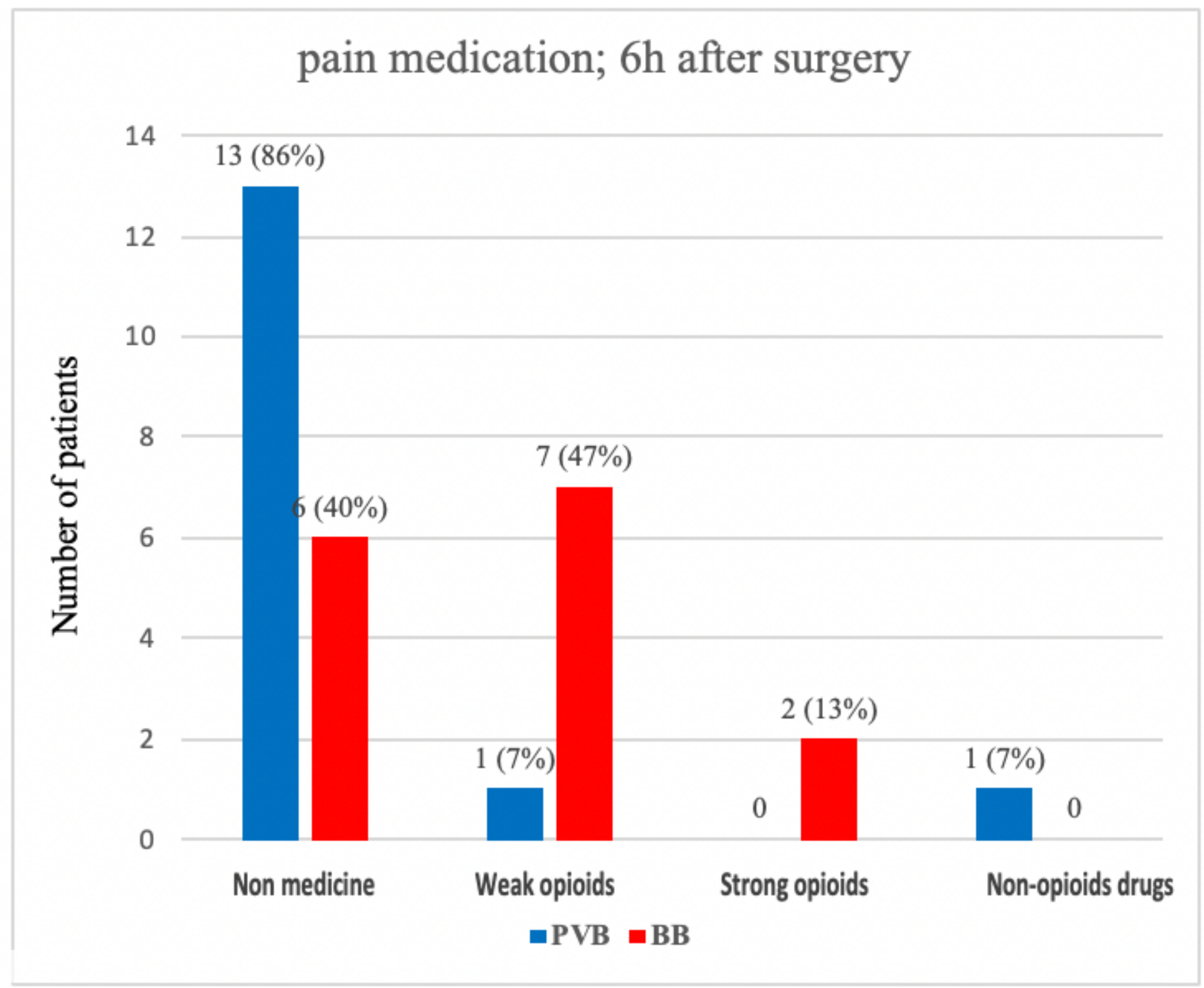

Figure 6

Pain medication Consumption 6 hours after surgery. 


\section{pain medication; $24 \mathrm{~h}$ after surgery}

14

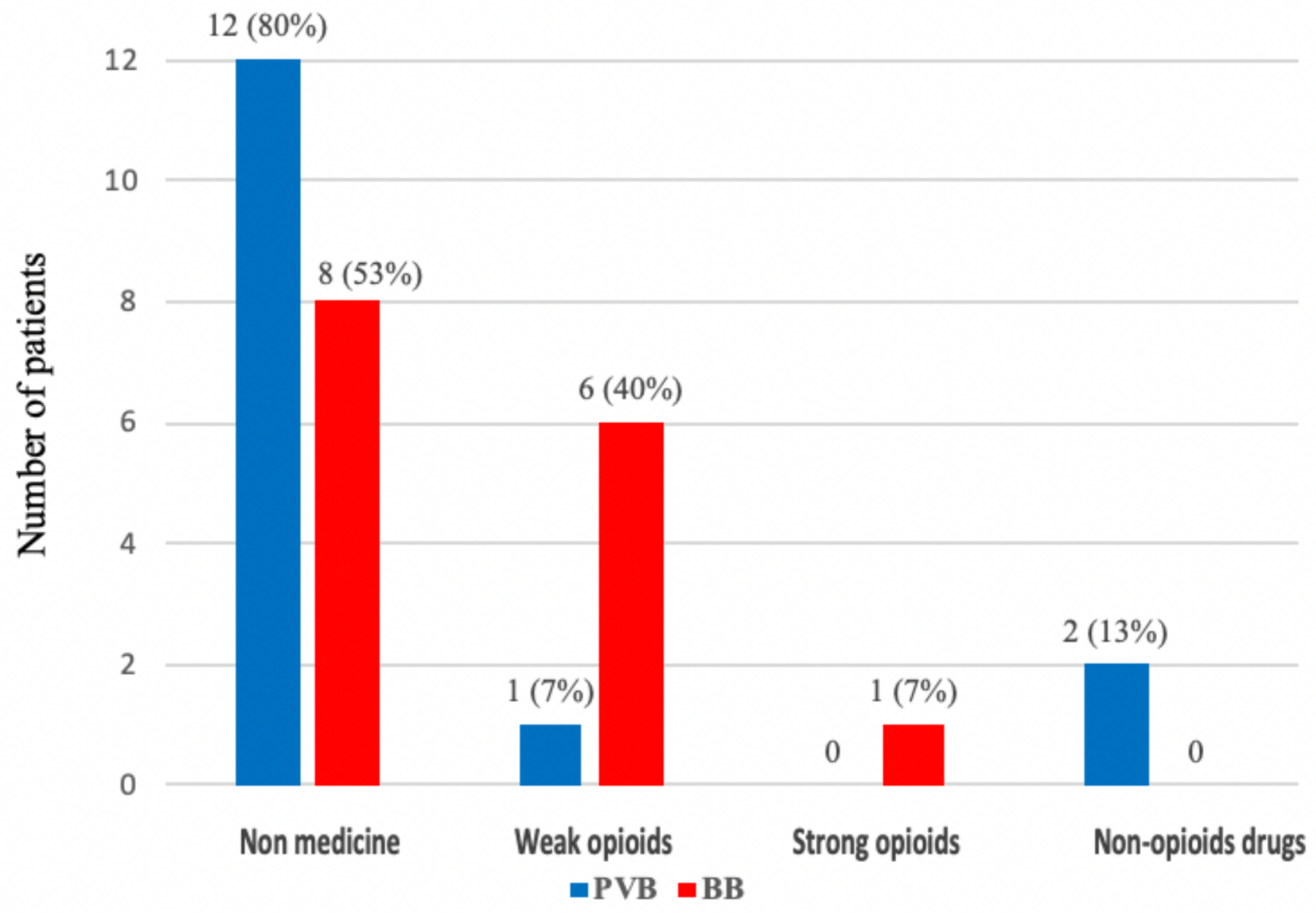

Figure 7

Pain medication Consumption $24 \mathrm{~h}$ after surgery. 


\section{Nausea and vomiting after surgery}

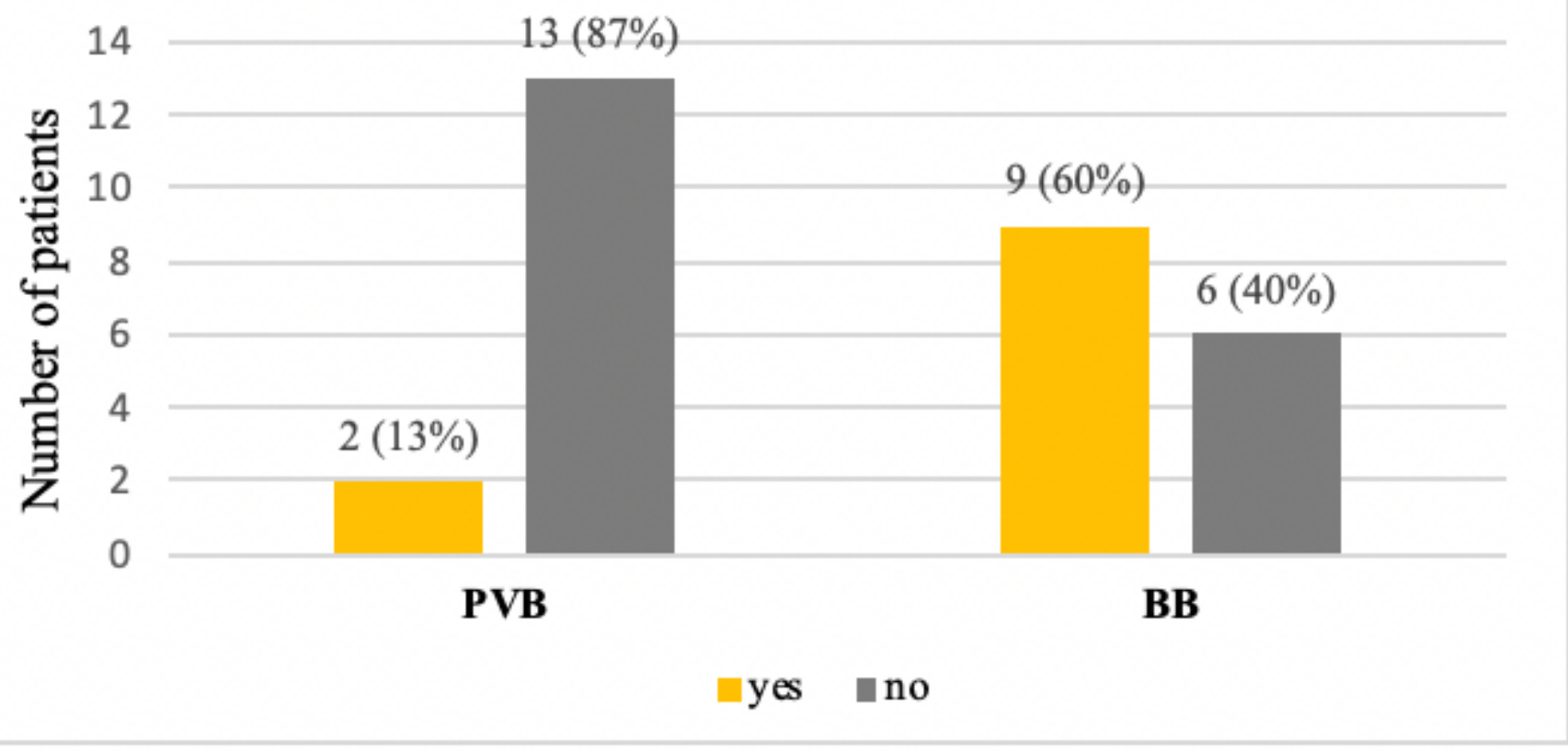

Figure 8

Adverse reactions in postoperative period.

\section{Supplementary Files}

This is a list of supplementary files associated with this preprint. Click to download.

- Checklist.pdf 